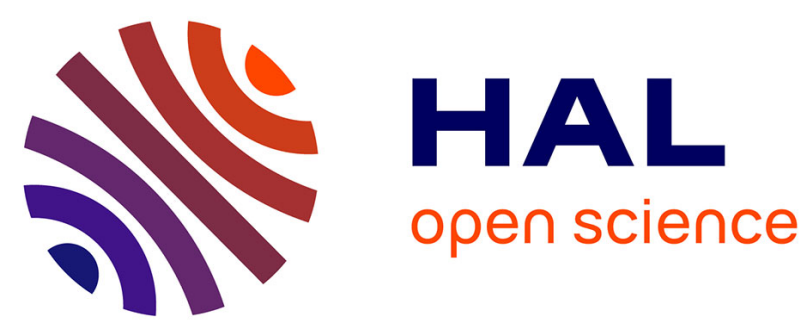

\title{
Clinical diagnosis of Alzheimer's disease: recommendations of the International Working Group
} Bruno Dubois, Nicolas Villain, Giovanni B Frisoni, Gil D Rabinovici, Marwan

Sabbagh, Stefano Cappa, Alexandre Bejanin, Stéphanie Bombois, Stéphane Epelbaum, Marc Teichmann, et al.

\section{To cite this version:}

Bruno Dubois, Nicolas Villain, Giovanni B Frisoni, Gil D Rabinovici, Marwan Sabbagh, et al.. Clinical diagnosis of Alzheimer's disease: recommendations of the International Working Group. The Lancet Neurology, 2021, 10.1016/S1474-4422(21)00066-1 . hal-03217875

\section{HAL Id: hal-03217875 \\ https://hal.sorbonne-universite.fr/hal-03217875}

Submitted on 5 May 2021

HAL is a multi-disciplinary open access archive for the deposit and dissemination of scientific research documents, whether they are published or not. The documents may come from teaching and research institutions in France or abroad, or from public or private research centers.
L'archive ouverte pluridisciplinaire HAL, est destinée au dépôt et à la diffusion de documents scientifiques de niveau recherche, publiés ou non, émanant des établissements d'enseignement et de recherche français ou étrangers, des laboratoires publics ou privés. 


\section{Clinical diagnosis of Alzheimer's disease: recommendations of the International Working Group (IWG)}

Bruno Dubois ${ }^{1,2,3 *}$ MD, Nicolas Villain ${ }^{1,2,3 *}$ MD, Giovanni B Frisoni ${ }^{4,5,6}$ MD, Gil D Rabinovici ${ }^{7}$ MD, Marwan Sabbagh ${ }^{8}$ MD, Stefano Cappa ${ }^{9,10} \mathrm{MD}$, Alexandre Bejanin ${ }^{11,12} \mathrm{PhD}$, Stéphanie Bombois ${ }^{1,13}$ MD, Stéphane Epelbaum ${ }^{1,3,14}$ MD, Marc Teichmann ${ }^{1}$ MD, Marie-Odile Habert ${ }^{3,15,16}$ MD, Agneta Nordberg ${ }^{17,18}$ MD, Kaj Blennow ${ }^{19,20}$ MD, Douglas Galasko ${ }^{21}$ MD, Yaakov Stern ${ }^{22}$ $\mathrm{PhD}$, Christopher C Rowe ${ }^{23}$ MD, Stephen Salloway ${ }^{24,25,26}$ MD, Lon S Schneider ${ }^{27}$ MD, Jeffrey L Cummings ${ }^{28,29}$ MD, Howard H Feldman ${ }^{30,31,32}$ MD

1. AP-HP Sorbonne Université, Hôpital Pitié-Salpêtrière, Department of Neurology, Paris, France

2. Sorbonne Université, GRC n ${ }^{\circ}$ 21, Alzheimer Precision Medicine, Paris, France

3. Institut du Cerveau - ICM, Sorbonne Université, INSERM U1127, CNRS 7225, Paris, France

4. Laboratory of Neuroimaging of Aging (LANVIE), University of Geneva, Geneva, Switzerland

5. Memory Clinic, University Hospital of Geneva, Geneva, Switzerland

6. Laboratory of Alzheimer's Neuroimaging and Epidemiology (LANE), Saint John of God Clinical Research Centre, Brescia, Italy

7. Memory \& Aging Center, Departments of Neurology, Radiology \& Biomedical Imaging, University of California San Francisco, San Francisco, CA, USA.

8. Cleveland Clinic Lou Ruvo Center for Brain Health, Las Vegas, NV, USA.

9. University School for Advanced Studies (IUSS), Pavia, Italy 
10. RCCS Mondino Foundation, Pavia, Italy

11. Memory Unit, Department of Neurology, Hospital de la Santa Creu i Sant Pau -

Biomedical Research Institute Sant Pau - Universitat Autonoma de Barcelona; Barcelona, Spain

12. Network Center for Biomedical Research in Neurodegenerative Diseases (CIBERNED); Madrid, Spain

13. Univ Lille, INSERM, CHU Lille, U1171 - Degenerative and vascular cognitive disorders, Lille, France

14. Inria, Aramis project-team, Inria-APHP collaboration, Paris, France

15. AP-HP Sorbonne Université, Hôpital Pitié-Salpêtrière, Department of Nuclear Medicine, Paris, France

16. Sorbonne Université, CNRS, INSERM, Laboratoire d'Imagerie Biomédicale, LIB, Paris, France

17. Department of Neurobiology, Care Sciences and Society, Center for Alzheimer Research, Karolinska Institutet, Stockholm, Sweden

18. Theme Aging, The Aging Brain, Karolinska University Hospital, Stockholm, Sweden

19. Institute of Neuroscience and Physiology, Department of Psychiatry and Neurochemistry, The Sahlgrenska Academy at the University of Gothenburg, Mölndal, Sweden

20. Clinical Neurochemistry Laboratory, Sahlgrenska University Hospital, Mölndal, Sweden

21. Department of Neurosciences, University of California, San Diego, La Jolla, CA, USA

22. Cognitive Neuroscience Division, Department of Neurology, Columbia University, New York, NY, USA

23. Department of Molecular Imaging and Therapy, Austin Health, The University of Melbourne, Melbourne, VIC, Australia 
24. Department of Neurology, Alpert Medical School of Brown University, Providence, Rhode Island, USA

25. Department of Psychiatry, Alpert Medical School of Brown University, Providence, Rhode Island, USA

26. Butler Hospital, Providence, Rhode Island, USA

27. Keck School of Medicine of the University of Southern California, Los Angeles, USA

28. Chambers-Grundy Center for Transformative Neuroscience, Department of Brain Health, School of Integrated Health Sciences, University of Nevada Las Vegas (UNLV) (JLC), Las Vegas, NV, USA

29. Cleveland Clinic Lou Ruvo Center for Brain Health (JLC), Las Vegas, NV, USA

30. Department of Neurosciences University of California, San Diego, La Jolla, CA, USA

31. Shiley-Marcos Alzheimer's Disease Research Center, University of California, San Diego, La Jolla, CA, USA

32. Alzheimer Disease Cooperative Study, University of California, San Diego, La Jolla CA USA

* Joint first authors

\section{Corresponding author:}

Prof. Bruno Dubois

Département de Neurologie

Groupe Hospitalier Pitié-Salpêtrière

47-83 boulevard de l'Hôpital

75651 PARIS Cedex 13, FRANCE

bruno.dubois@aphp.fr 
tel: 33142167540 


\begin{abstract}
(175)
In 2018, the National Institute of Aging and the Alzheimer Association proposed a purely biological definition of Alzheimer's disease (AD) relying on biomarkers. While the intended use of the framework was for research purposes, it has engendered debate and challenges regarding its application in everyday clinical practice. For instance, cognitively unimpaired individuals may have biomarker evidence of both amyloid and tau pathology, but may never develop clinical manifestations in their lifetime. Furthermore, a positive AD pattern may be observed in other brain diseases where AD pathology is present as co-morbidity. In this Personal View, the international Working Group (IWG) presents what we consider to be the current limitations of biomarkers in the diagnosis of $\mathrm{AD}$, and on the basis of this evidence we propose recommendations for how biomarkers should and should not be used for diagnosis of $\mathrm{AD}$ in a clinical setting. We recommend that $\mathrm{AD}$ diagnosis be restricted to the occurrence of positive biomarkers together with specific $\mathrm{AD}$ phenotypes, whereas biomarker positive cognitively unimpaired individuals should be considered only at-risk for progression to AD.
\end{abstract}

“Search strategy" box. Search strategy and selection criteria for this Review were identified by searches of PubMed between January $1^{\text {st }} 2018$ and July $1^{\text {st }} 2020$, and references from relevant articles. The search terms "biomarker", “amyloid”, “tau”, “neurodegeneration”, "preclinical”, "CSF", "PET", "subjective cognitive decline" in the context of "Alzheimer's disease" and "ATN classification" were used. There were no language restrictions. The final reference list was generated on the basis of relevance to the topics covered in this Review. This Review identifies conceptual and practical limitations of its utility and appropriateness for application in clinical practice. 


\section{Introduction}

In 2018, the National Institute of Aging (NIA) and the Alzheimer Association (AA) proposed the amyloid, tau, neurodegeneration (ATN) research framework for the definition and diagnosis of Alzheimer's disease (AD) ${ }^{1}$. This framework has enabled the move from a clinical-biological diagnosis to a purely biological definition of $\mathrm{AD}$ that can be applied in both the asymptomatic and symptomatic stages of the disease. The increased accessibility to biomarkers and the perspective to have blood-based information on the underlying pathophysiological process in the future make it necessary to consider the limitations of biomarkers in the diagnosis of AD and to propose recommendations for how these biomarkers might and might not be used for the diagnosis of $\mathrm{AD}$ in a clinical setting.

\section{I - Evolution of the diagnostic frameworks for Alzheimer's disease}

Over the last 15 years, there has been a remarkable evolution in the development and availability of in-vivo AD biomarkers, in the characterization of the natural history of the disease, and in turn in the application of this new knowledge to revised diagnostic research frameworks for AD (see Table 1). The first revision to the National Institute of Neurological and Communicative Disorders and Stroke and the Alzheimer's Disease and Related Disorders Association criteria ${ }^{2}$ was provided by the International Working Group (IWG) in $2007^{3}$. It was the first research framework to propose $\mathrm{AD}$ as a clinical-biological entity based on in-vivo biomarkers with specific clinical phenotypes of $\mathrm{AD}$ and to extend the definition to the prodromal (predementia) dementia stages. In 2010, the IWG introduced a new supporting lexicon for AD with recommendations in the classification of the preclinical stages without symptoms ${ }^{4}$ including a) "asymptomatic at-risk" for those with biomarker evidence of Alzheimer pathology; b) "presymptomatic" for those carrying monogenic AD mutations ${ }^{4}$. The next important development 
occurred in 2011 with the NIA-AA criteria that defined three different preclinical stages, according to the amyloid cascade hypothesis: amyloid lesions first, then tau pathology causing neurodegeneration, and finally occurrence of subtle cognitive changes ${ }^{5,6}$. In 2016, an IWG and NIA-AA consensus advanced the classification scheme to include AD for research purposes diagnosed at a preclinical stage of the disease, on the presence of both in-vivo amyloid and tau positivity "where the risk of a further progression to clinical AD is high", a proposal that was further developed by Jack and collaborators ${ }^{1,8}$. In the latest 2018 NIA-AA diagnostic framework, AD diagnosis is centred exclusively around a biomarker definition of disease according to ATN status $^{1}$. Even in the absence of any cognitive symptoms, those subjects having both abnormal amyloid and tau biomarkers $(\mathrm{A}+\mathrm{T}+)$ were defined as 'Alzheimer's disease'.

The development of 'positive' in-vivo biomarkers has moved the field from diagnosing AD at the dementia stage, towards earlier AD diagnosis at the prodromal stage, and have introduced the potential for preclinical diagnosis. These developments are particularly relevant in advancing testable therapeutic hypotheses towards secondary prevention of AD.

\section{II - Limitations of a purely biological definition of AD}

These 2016 consensus meeting and 2018 criteria $^{1,7}$ have engendered significant debate about applying a biomarker-based disease diagnosis, with clinical symptoms and phenotype being used only for staging ${ }^{9,10}$. Four years after their introduction, a reevaluation of a diagnostic approach based only on biological markers is warranted, both on conceptual and evidence-based practical levels.

\section{Risk of confusion between presence of brain lesions and disease}


Based on $\mathrm{A} / \mathrm{T} / \mathrm{N}$ definition, $\mathrm{AD}$ may be considered as a purely biological condition, dissociated from a clinical component or patient status. By dissociating $\mathrm{AD}$ from a clinical phenotype, the disease equates to $\mathrm{AD}$ neuropathologic changes, whereas in 2012, neuropathologists stated that “There is consensus to disentangle the clinicopathologic[al] term 'Alzheimer's disease' from [Alzheimer's disease] neuropathologic[al] change" ${ }^{11}$. As a consequence, it provides a classification, which gathers under the same label - AD - an extended continuum from cognitively normal individuals to severely demented patients.

\section{Low predictive accuracy (Panel 1)}

A major limitation of a purely biological definition of $\mathrm{AD}$ is the lack of predictive accuracy. Several recent studies indicate that the presence of tau and amyloid positivity is insufficient to definitively predict the invariable occurrence of symptoms (mild cognitive impairment [MCI] or dementia) in those subjects without clinical impairment (evidence is summarized in Panel 1). Another challenge to a biomarker-only diagnosis of $\mathrm{AD}$ is that the presence in-vivo of biomarkers of $\mathrm{AD}$ lesions may not certify the existence of $\mathrm{AD}$ as the primary diagnosis: such lesions are a frequent co-pathology in other neurodegenerative diseases, dementia with Lewy bodies (DLB) being most frequent ${ }^{12}$. These patients should not be considered as having a primary diagnosis of AD. These exemplars of co-pathologies will create potential confusion for those receiving a biomarker-based diagnosis in such circumstances.

\section{Presence of other pathologies}

Conversely, neuropathologically-defined $\mathrm{AD}$ is frequently associated with other pathologies. Pure AD pathology is the exception rather than the rule in autopsy cases $(\sim 3-30 \%$ of cases according to age $^{12}$ ). $\mathrm{AD}$, as described years ago in its "pure" form, is a model that may not apply especially in late-life dementia where multiple proteinopathies are more frequent. Co- 
pathologies, including synucleinopathy, vascular pathology, non-AD tauopathies - in particular argyrophilic grain disease and cortical aging-related tau astrogliopathy - and TAR DNA binding protein 43 (TDP-43) pathology - in particular limbic-predominant age-related TDP-43 encephalopathy [LATE] neuropathological changes - influence significantly both clinical trajectory and phenotypes of $\mathrm{AD}(\sim 50-60 \%$ of dementia of the Alzheimer type cases are estimated to be attributable to these co-pathologies) ${ }^{12-16}$. Unfortunately, pathological biomarkers are currently unavailable for the non-AD proteinopathies, and disentangling AD from non-AD neurodegenerative diseases remains phenotypic or cannot be achieved in life.

\section{Uncertainty regarding the pathogenesis model of AD}

The biological model that supports the A/T/N classification opens up the possibility for research into the biological changes prior to the onset of symptoms, which is necessary to develop drugs for the earliest stage. Advocates for a biological definition of AD often refer to the cancer model where a long asymptomatic phase of the disease can exist and where all affected patients, located anywhere along this disease continuum, will benefit from the same therapeutic approach even at a preclinical stage. However, the follow-up of cognitively unimpaired biomarker positive individuals suggests that they do not all progress overtime. At the present time, the determination of whether $\mathrm{AD}$ fits better with the long and asymptomatic 'prostate cancer' continuum or with an at-risk model of the disease (where the asymptomatic $(\mathrm{A}+\mathrm{T}+)$ would be the at-risk state, i.e. the precancerous condition, and where clinical phenotype would be the disease state, i.e. the cancer state) is not yet determined.

Finally, defining the disease by its pathological lesions only - and not by a clinical phenotype leads to the risk of creating confusion particularly within the healthy oldest old where memory complaints and low levels of AD pathology are the rule ${ }^{17,18}$. Publications in the field of dementia, 
which propose that the disease is a myth ${ }^{19}$ or a decoy ${ }^{20}$, illustrate the potential for confusion between $\mathrm{AD}$ and old age.

Taken together, these data indicate that amyloid and tau biomarkers are not sufficient to confidently predict the trajectory towards prodromal $\mathrm{AD}$ or $\mathrm{AD}$ dementia to define the $\mathrm{AD}$ continuum without clinical input. The relationships between co-occurrence of tau and amyloid pathology on the one hand, and the development of cognitive decline and neurodegeneration on the other hand remain uncertain at an individual level. Besides the dominating amyloid cascade model, additional pathogenesis models have been advanced, including the role of endosomal recycling deficiency ${ }^{21}$, of immunity, of lipid metabolism and endocytosis deficiency ${ }^{22}$, of vascular dysfunction ${ }^{23}$, etc.

\section{Difficulty in classifying cognitively unimpaired biomarker positive subjects (Panel 2)}

The challenge to a purely biological definition of $\mathrm{AD}$ is mostly centred on the preclinical stage of the disease, i.e. in conditions where, by definition, cognitive testing does not support the presence of an $\mathrm{AD}$ phenotype. In case of symptomatic patients, the identification of the specific clinical phenotype (interfering or not with independence in everyday activities) is a major step for the diagnosis as it expresses the brain dysfunction that the biomarkers are signalling. Cognitively unimpaired individuals with biomarker positivity are not invariably doomed to subsequent cognitive decline: the best current estimates of lifetime dementia risk range from $5 \%$ to $42 \%{ }^{24}$. Because of the uncertainty of their evolution over time (Panel 1), asymptomatic individuals who are biomarker positive should be classified as "at-risk for progression" - ARP - distinguishing two different subgroups for clinical and research purposes:

A) Some individuals will remain stable over long periods of time: this subgroup includes people who may never develop symptoms. These persons may compensate and maintain normal 
functioning for many years even in the presence of an on-going neurodegenerative process, or some may have no accelerated neurodegeneration despite $\mathrm{AD}$ brain lesions. ${ }^{25}$

B) Other will progress: this subgroup includes individuals who demonstrate signs of accelerated neurodegeneration and whose compensatory mechanisms are overcome. They can be reliably predicted to progress to prodromal $\mathrm{AD}$ and $\mathrm{AD}$ dementia in the future.

For research purposes, both subgroups have to be separated in order to define factors of prevention and to develop algorithms to predict progression. This risk of progression depends on several modulating factors whose magnitude and interactions still remain to be determined (see Panel 2). These factors are either risk markers or risk factors and are related to brain resilience (e.g. cognitive reserve) and resistance ${ }^{25}$, biological and genetic factors that are directly related to the amyloid, tau, and their neurodegeneration-induced pathways (genetic protection and risk factors regarding tau binding proteins and amyloid precursor protein metabolism; protection and risk factors related to immunity, endocytosis, and lipid metabolism ${ }^{26-30}$; newly described brain cellular senescence mechanisms ${ }^{31}$ ), and co-pathology. For instance, is a 60-year-old APOE $\varepsilon 4$ carrier with a negative tau PET and an amyloid PET scan just below the threshold at less risk than an 85-year-old who is $\mathrm{A}+\mathrm{T}+$ with cerebrovascular lesions on MRI? We anticipate the emergence of age- and risk factor-adjusted individualized predictions and the ability to rank the risk by analogy with the example of cardiovascular risk factors ${ }^{32}$. Such modelling is in its early stages but exemplified through the example of age adjusted polygenic hazard scores ${ }^{33}$. However, disclosing individual patient-level risk with the current state of knowledge is premature and to be avoided as current individualized prediction models perform insufficiently well in cognitively unimpaired subjects compared to those in the prodromal stage of $\mathrm{AD}^{34}$. Besides conceptual issues, there are several practical aspects that may limit the use of biomarkers for the pure 
biologically-based diagnosis of AD. They concern the thresholds, generalization, metric performance, accessibility, amongst others.

\section{Biomarker thresholds}

A biological diagnosis of $\mathrm{AD}$ that is linked to positive biomarkers brings the invariable need to define and be certain about thresholds and cut-off points of positivity, as any modification of these thresholds would significantly impact both the diagnosis and the stages of the disease. The clear-cut separation between negative and positive subjects in relation to a given biomarker is somewhat artificial and different from one site or one study to another. Factors contributing to this uncertainty include the specifics of the biomarker used as well as the threshold determination. Most of all, this binary threshold does not reflect the reality of amyloid and tau pathology which is continuous and present at a minimal level in almost all the aging population ${ }^{18}$, with important discrepancies between pathology burden and clinical symptoms at intermediate levels (Panel 1). It is noteworthy that neuropathology criteria of AD provide no cut-off for establishing AD but only define 'low, intermediate or high' levels of AD neuropathologic change $\mathrm{e}^{11}$.

For amyloid biomarkers, the use of binary thresholds of amyloid PET standard uptake value ratio (SUVR) has long restricted the measure of amyloid to intermediate and high levels of amyloid deposition ${ }^{35}$. The use of different amyloid PET tracers is also a known factor of variability in measurements, though the centiloid quantification approach helps at diminishing its impact ${ }^{36}$. Recent works (using the centiloid scale or longitudinal amyloid PET) open the possibility to identify earlier stages of amyloid accumulation ${ }^{37,38}$. In CSF, a positive amyloid measure despite a negative amyloid PET or the use of novel biomarkers (for instance, CSF A $\beta 34 / 42$ ratio $^{39}$ ) might also prove to be reliable biomarkers of early amyloid deposition stages $^{39,40}$. 
For tau biomarkers, there is also a strong discrepancy between neuropathological identification (in post-mortem studies, the presence of tau Braak stages I-II is almost universal after the age $70)^{18,41}$ and in-vivo measures of tau aggregates on PET $(\sim 36 \%$ of $(\mathrm{T}+)$ detected after the age of $70^{42}$ ). The current in-vivo definition ability of tau PET to detect 'tau positivity' using flortaucipir PET seems to correspond only to widespread tau pathology in the brain (i.e. Braak stages $\geq \mathrm{IV})^{43}$, while CSF phospho-tau (p-tau) elevation may reflect earlier stages of tauopathy ${ }^{44}$. In the near future it might become possible to have in-vivo tau measurements that detect very early tau deposits, i.e. tau Braak stages I-II with $2^{\mathrm{d}}$ generation tau PET tracers or by detecting other phosphorylated species of tau such as p-tau 217 in the CSF or the plasma ${ }^{45}$. In clinical practice, such an extension to "earlier" thresholds in amyloid or tau biomarkers may lengthen the duration of the asymptomatic stages and decrease the lifetime clinical progression probability. Biomarkers thresholds also depend on the intended use and no consensus on the context of use is currently available ${ }^{1}$.

On the other hand, evaluating cognitive changes and determining the stages in patients with $\mathrm{AD}$ (i.e. identification of objective cognitive impairment, $\mathrm{MCI}$ or dementia) also raise threshold issues. The emergence of lower thresholds in cognitive testing to define the 'objective subtle cognitive changes' entity further extends the clinical stages of neurodegenerative diseases, before the occurrence of $\mathrm{MCI}^{6}$. However, this increased sensitivity in the detection of cognitive decline comes at the expense of a reduced specificity, and numerous other etiologies can be responsible for the observed changes, such as personality traits, psychiatric disorders, and sleep apnea amongst others ${ }^{46}$.

\section{Generalization and accessibility in clinical practice}

Considering general medical practice and standard of care, the six currently available Cochrane reviews regarding the use of CSF or amyloid PET biomarkers have consistently led to the same 
conclusion: "we cannot recommend the routine use of [these biomarkers] in clinical practice"47${ }^{52}$. These reviews considered the ability of-biomarkers to predict the future occurrence of clinical $\mathrm{AD}$ dementia in patients with MCI. Their recommendation answers the pragmatic question in clinical practice: “will my patient decline?". As underscored by the Cochrane reviews, the prognostic value of biomarker diagnosis remains limited by the fact that 1) there is a high variability of decline rate amongst biomarker-positive $\mathrm{AD}$ patients ${ }^{53}$ and 2) non- $\mathrm{AD}$ neurodegenerative diseases contribute to cognitive decline. The Cochrane reviews further point out the "the heterogeneity in the conduct and interpretation of the biomarkers and the lack of defined thresholds for determination of test positivity". The choice of lower or higher biomarker thresholds correspond to earlier or later pathological burden and may change the duration of the asymptomatic stages and decrease the lifetime clinical progression probability. Finally, the Cochrane reviews underline the high financial cost of PET exams and the invasiveness of CSF measurements, which limit their interest and applicability in clinical practice, especially in lowincome countries.

While these limitations were highlighted for patients with MCI, but data are even more sparce for cognitively unimpaired individuals as available currently models are lacking in the clinical setting, especially in cognitively unimpaired subjects. As seen in Panel 1, the magnitude effect of biomarker positivity on clinical progression remains weak to moderate and was established on selected volunteers from research cohorts. The generalization of these cohort findings to clinical practice also faces several obstacles: the risk of attrition bias from these data is strong, especially in the Alzheimer's Disease Neuroimaging Initiative (ADNI) cohort with many individuals lost to follow-up ${ }^{54}$, and the risk of selection bias is even stronger since individuals included in these longitudinal cohorts were usually selected by advertisement and do not represent the variety of individuals in clinical practice to whom the biomarker investigations will be applied. 
An increasing number of persons now seek consultation in memory clinics complaining of subjective memory problems or cognitive decline (SCD) while scoring normally on formal cognitive testing. SCD may be a risk factor of clinical progression ${ }^{55}$ but the magnitude of prediction ability of SCD regarding cognitive decline remains low (OR $\sim 1.5-3^{56}$ ). SCD may result from many factors besides aging: anxiety, depression, fatigue, sleep disorders, attention deficits, and drug side effects amongst others ${ }^{57}$. In this regard, it is noteworthy that the frequency of CSF AD profiles between those with normal cognition and SMC is similar ${ }^{58}$. The heterogeneity of this population is important according to the nature of complaint (self-report versus report by an informant) and to the cognitive status (normal cognition versus subtle cognitive changes) ${ }^{17}$.

Other individuals do not report cognitive problems and may be just worried about future cognitive decline due to family history, results from commercial direct-to-consumer genetic testing or $A P O E$ status, or simply concerned about preserving their memory and general cognitive abilities (sometimes referred to as "worried well" patients). Such individuals are seeking to understand their risk and their future. They represent up to $20-30 \%$ of new patients in some specialty memory clinics ${ }^{59-61}$ and in some of these cases, biomarker investigations may have been performed. In these situations, reliance on a biomarker-only diagnosis would require a very secure and tightly elaborated natural history connecting the positivity of biomarkers with an invariable - or at least extremely high probability of - subsequent expression of clinical symptoms. This is not the case today. Recent experience with the Sokrates study underscores some of the uncertainties (e.g. inability to make an accurate short- or medium-term prediction about cognitive decline for an individual), which are inherent in revealing amyloid PET results alone to cognitively unimpaired individuals ${ }^{62}$. This issue also applies for patients who may 
undergo a work-up for other medical conditions where AD biomarkers are included in the absence of any clinical context, and are positive ${ }^{63}$.

As a whole, evidence for the use of biomarkers in clinical practice remains highly disputed and suffers from a lack of evidence-based data to recommend biomarker assessments for those with subjective memory complaints (SMC).

\section{Ethical concerns}

Diagnostic disclosure is ethically challenging when physicians inform cognitively unimpaired individuals that they have an irreversible disease based on biomarkers when the clinical trajectory towards prodromal $\mathrm{AD}$ or $\mathrm{AD}$ dementia is uncertain and where there is no way to significantly prevent the development of symptoms in the absence of modifiable risk factors or specific therapies ${ }^{64}$. Disclosing biomarker results and the related risk profile should be seen as different from disease diagnosis disclosure. Within the lay community, AD is amongst the most feared diseases given its outcomes including profound disability and loss of personal dignity ${ }^{65}$. A discourse by physicians where $\mathrm{AD}$ equates $\mathrm{AD}$ neuropathological changes is profoundly discrepant with patients' narratives where $\mathrm{AD}$ equates dementia, dependency, and death, and this can adversely impact the therapeutic alliance ${ }^{9}$. In the future, being said to be 'at-risk for progression' instead of 'in the preclinical stage of AD' may help in the discussion of the 'RiskBenefit balance' regarding a putative treatment and its side effects.

\section{III- The IWG recommendations for the clinical setting}

Based on this evidence, the IWG proposes the following recommendations:

1. The diagnosis of AD is clinical-biological. It requires the presence of both a specific clinical phenotype of $\mathrm{AD}(\mathrm{P}+)$ and biomarker evidence of AD pathology $(\mathrm{A}+\mathrm{T}+)$. 
2. Specific clinical phenotype commonly associated with AD pathology (common AD phenotypes) are: the amnestic syndrome of the hippocampal type ${ }^{66}$ (typical), the posterior cortical atrophy variant $^{67}$, and the logopenic variant primary progressive aphasia ${ }^{68,69}$ (Supplementary Figure 1). Other phenotypes, including the behavioural/dysexecutive variant $^{70,71}$, the cortico-basal variant ${ }^{72,73}$, and the other variants of primary progressive aphasia $^{69,74}$ (Supplementary Figure 1), are less commonly related to AD pathology (uncommon $\mathrm{AD}$ phenotypes). These phenotypes may or may not interfere with independence in everyday activities.

3. With these common phenotypes, amyloid, and tau biomarkers positivity establishes an AD diagnosis (Table 2). The positivity of both amyloid and tau biomarkers is required because an amnestic phenotype with only amyloid positivity is not specific to AD, being observed in other neurodegenerative diseases with amyloid co-pathology, including LATE, DLB, etc ${ }^{1,12,75}$ or in patients with cerebral amyloid angiopathy and amnestic vascular cognitive impairment ${ }^{76}$ (Supplementary Figure 1). On the other hand, an isolated amnestic syndrome of the hippocampal type with only tau biomarker positivity can be encountered in primary age-related tauopathy (PART) $)^{77,78}$ or in atypical presentations of mixed 3R/4R frontotemporal lobar degeneration (FTLD) tau ${ }^{75,79}$ (Supplementary Figure 1). Finally, uncommon phenotypes with positive AD biomarkers should not be a priori classified as an established AD (Table 2): in such cases the clinician may deem that AD is not the dominant pathology driving the clinical phenotype but only a copathology.

4. Recommended biomarker measures for amyloid pathology are low CSF A $\beta 42$, increased CSF $A \beta 40 / 42$ ratio (which is, if possible, preferred to low CSF A $\beta 42$ ), or increased tracer retention in amyloid PET; for tau pathology, we recommend high CSF p-tau (not total tau 
[t-tau] due to its lack of specificity ${ }^{80}$ ) or increased ligand retention in tau PET. Amyloid and tau PET recommendation for use in clinical practice is conditional on regulatory approval and reimbursement by payers in different countries.

5. Diagnosis conclusion requires clinician expertise in both the critically assessment of clinical and biomarker results. The different situations encountered in clinical practice are summarized in Table 2. In the case of cognitive testing and/or biomarkers in the 'grey zone', it may be useful to complete the workup with another investigation (repeated measure of pathophysiological biomarker, clinical follow-up, use of neurodegeneration biomarkers such as FDG-PET, etc).

6. CSF investigation is prioritized as it provides simultaneous information on the 2 types of biomarkers (amyloid and tau) and is less expensive than amyloid-PET and/or tau-PET. Where lumbar puncture is contraindicated, PET investigations are an alternative consideration.

7. In clinical practice, plasma biomarkers for amyloid and tau pathology are not currently recommended. Although promising, they require further standardization and validation before they can be broadly regarded as secure biomarker evidence of AD pathology $(\mathrm{A}+\mathrm{T}+)^{45,81}$.

8. In clinical practice, the investigation of pathophysiological biomarkers in cognitively unimpaired individuals is not recommended, given their current inability to predict reliable clinical trajectories of those who are asymptomatic with biomarker positive status $(\mathrm{A}+\mathrm{T}+)$. In the future, if therapies or prevention programs show significant efficacy in delaying onset of disease it will probably change the need for biomarker investigations in 
these individuals, although the problem of the prediction of clinical trajectories in cognitively unimpaired biomarker positive individuals will still remain.

9. In cases where a biomarker investigation is performed in cognitively unimpaired individuals (for any specific situations: will to know, brain health services, expert centres, research project, cohort study, diagnostic workup for other conditions...), a risk stratification of biomarkers is proposed (Panel 3) distinguishing an absolute risk group (carriers of autosomal dominant monogenic mutations for AD $)^{82}$, a high-risk group ${ }^{42}$, and an undefined risk group, to be further clarified in the future as additional evidence accrues $^{55,83,84}$. The proposed stratification is a starting point for research purposes. Validation studies on large cohorts with long periods of follow-up are needed. The challenge for the future is to reliably and predictably define the level of risk for further progression.

In these situations, subjects should be counselled before $\mathrm{AD}$ biomarker investigation so that they can be informed of the ins and outs of the test results and can decide whether or not the result will be disclosed. If they decide to receive the results and they return positive, subjects should be counselled that they are at-risk for subsequent clinical progression (ARP) to prodromal $\mathrm{AD}$ or $\mathrm{AD}$ dementia and not clinically diagnosed as having AD.

10. SMC and SCD, when isolated and not supported by objective cognitive impairment, are not specific enough to be considered as part of the AD phenotype ${ }^{85}$. In cognitively unimpaired individuals, self-reported complaints and complaints reported by an informant should be clearly distinguished as the latter are more at-risk of progression ${ }^{86}$ and merit a closer follow-up with regular clinical and neuropsychological evaluations. 
11. Alzheimer's disease can be associated with other brain pathologies, including synucleinopathy ${ }^{28}$, vascular pathology, non-AD tauopathies, and TDP-43 pathology ${ }^{12-15}$. Alternatively, lesions of the Alzheimer type are frequently observed as co-pathology in post-mortem examination of other neurodegenerative diseases ${ }^{12,69,71}$. In both situations, pathophysiological AD biomarkers can be positive ${ }^{87}$. This is particularly ambiguous in the case of behavioural variant frontotemporal dementia (bvFTD), cortico-basal syndrome (CBS), semantic or non-fluent variants of primary progressive aphasia where the presence of positive $\mathrm{AD}$ biomarkers can be considered either as $\mathrm{AD}$ co-pathology or atypical forms of $\mathrm{AD}^{69,71,73,74}$ (Supplementary Figure 1). In all these situations, it is recommended that the physician relies more on the phenotype and follow-up to determine the final diagnosis (AD or co-pathology) (Table 2). In some complex cases, only post-mortem evaluation will provide definitive information.

12. It is recommended that the physician objectively evaluates the added-value of biomarker investigation for each symptomatic patient according to the clinical situation (age, risk of comorbidity, complexity of the phenotype), the life context, the wishes of the patient to know the most likely diagnosis, the possibility to participate in a disease-modifying trial, and more globally the appreciation of how exactly this information will change the management of the patient. Biomarker investigations may also be limited by the availability, cost, and health care payment coverage of biomarkers across countries and centres as well as clinical situations.

13. When pathophysiological biomarkers are not available, patients should have a clinical syndromic diagnosis: 'amnestic AD phenotype' or 'logopenic variant primary progressive aphasia' etc ( $\mathrm{P}+$ with $\mathrm{A}$ and $\mathrm{T}$ unknown), where staging (MCI or dementia) may still be applied. In these situations, more attention should be given to rule out non-degenerative 
causes $^{75}$. If a positive neurodegeneration biomarker (FDG-PET hypometabolism, T1-MRI atrophy, CSF NFL, etc) is associated with a common AD phenotype, the term 'neurodegenerative disease of Alzheimer type' can be used (Table 2).

\section{Conclusion}

While the definition of AD based exclusively on biological markers has gained significant traction in research settings, emerging studies suggest that the biomarker definition is not ready for application in clinical settings and for diagnosis of individuals without cognitive impairment. The evidence of the natural history of those asymptomatic at-risk with positive biological markers is insufficient to predict subsequent cognitive decline and dementia. In light of these findings, we provide recommendations for diagnosis and disclosure in the clinical setting which avoid labelling $\mathrm{AD}$ in individuals who are biomarker positive and cognitively unimpaired and who are at-risk for progression to prodromal $\mathrm{AD}$ or $\mathrm{AD}$ dementia. We recommend that the diagnosis of $\mathrm{AD}$ in the clinical setting remains tied to the clinical phenotypic presentation. There are several critical requirements to achieve the utility of biomarkers to predict progression to clinical stages of $\mathrm{AD}$. The first is the relationship between pathological burden, biomarker thresholds, and the respective impact and weight of modulating factors in relation to future risk of clinical progression. The second concerns the pathogenesis of $\mathrm{AD}$ itself. As detailed above, data suggest that $\mathrm{AD}$ may result not only from tau and amyloid pathologies but from synergy and interactions among these pathologies which lead to the highest stages of protein accumulation, the highest rates of cognitive decline. Investigating such synergies and understanding protective factors in those who are asymptomatic with biomarkers of $\mathrm{AD}$ pathology represent both a direction to better define the disease and to prevent it in the future. 


\section{Glossary of terms}

Alzheimer's disease: a clinico-biological entity defined by a specific clinical phenotype (either typical or atypical) associated with in-vivo evidence of Alzheimer's pathology

Alzheimer's pathology: can be approached today in-vivo by biomarkers of amyloid pathology (decreased $A \beta 42$ or elevation of $A \beta$ 1-40/A $\beta$ 1-42 ratio in CSF; increased tracer retention in amyloid PET) and of tau pathology (increased P-tau in CSF; increased tracer retention in tau PET).

Prodromal Alzheimer: refers to the early symptomatic and pre-dementia phase of AD.

Alzheimer dementia: refers to the phase of AD where cognitive symptoms are sufficiently severe to interfere with social functioning and instrumental activities of daily living.

Typical AD: refers to the most frequent clinical phenotype of AD that is characterized by an initial progressive and predominant episodic memory deficit (not normalized by retrieval facilitation) and is followed by or associated with other cognitive impairments (executive dysfunction, language, praxis and complex visual processing impairments) and neuropsychiatric changes.

Atypical AD: refers to the less frequent clinical phenotypes of AD. These clinical syndromes include logopenic variant primary progressive aphasia, posterior cortical atrophy, behavioural/dysexecutive variant, cortico-basal syndrome, and the other variants of primary progressive aphasia.

Common AD phenotype: refers to the phenotypes where AD pathology is the most common underlying primary pathology. These phenotypes include amnestic $\mathrm{AD}$, logopenic variant primary progressive aphasia, and posterior cortical atrophy.

Uncommon AD phenotype: refers to the phenotypes where AD pathology can be uncommonly the underlying primary pathology (common underlying primary pathology include FTLD-Tau, FTLD-TDP, etc). These phenotypes include behavioural/dysexecutive variant, cortico-basal syndrome, and other variants of primary progressive aphasia.

Neurodegenerative disease of Alzheimer type: refers to cases where pathophysiological biomarkers are missing and common AD phenotypes are observed together with neurodegeneration biomarkers (FDG-PET hypometabolism, T1-MRI atrophy, CSF NFL, etc).

Asymptomatic at-risk (ARP): refers to cognitively unimpaired individuals who have in-vivo evidence of Alzheimer's pathology. Some can remain stable over long period of time. Other will progress.

Pathophysiological biomarkers: refer to in-vivo biological changes that reflect the underlying Alzheimer's pathology. They are markers of diagnosis, more targeted at identifying AD. 
Markers of neurodegeneration: refer to topographical biomarkers or downstream markers. They can be structural (atrophy/MRI) or metabolic (hypometabolism/FDG-PET). They are more targeted at assessing changes over time and predicting outcomes.

Clinical-biological diagnosis: refers to a diagnosis based on both clinical and biomarker findings.

Biological diagnosis: refers to a diagnosis only based on biomarker evidence

Co-pathology: co-morbid pathological changes superimposed to a primary pathological diagnosis.

Prevention of AD: becomes a major challenge. Discovery of pathophysiological biomarkers makes possible to distinguish:

- Primary prevention based on interventions before the presence of positive AD biomarkers

- Secondary prevention based on interventions performed when positive biomarkers are present. 


\section{REFERENCES}

1 Jack CR, Bennett DA, Blennow K, et al. NIA-AA Research Framework: Toward a biological definition of Alzheimer's disease. Alzheimer's Dement 2018; 14: 535-62.

2 McKhann G, Drachman D, Folstein M, Katzman R, Price D, Stadlan EMM. Clinical diagnosis of Alzheimer's disease: Report of the NINCDS-ADRDA Work Group* under the auspices of Department of Health and Human Services Task Force on Alzheimer's Disease. Neurology 1984; 34: 939-939.

3 Dubois B, Feldman HH, Jacova C, et al. Research criteria for the diagnosis of Alzheimer's disease: revising the NINCDS-ADRDA criteria. Lancet Neurol 2007; 6: 734-46.

4 Dubois B, Feldman HH, Jacova C, et al. Revising the definition of Alzheimer's disease: a new lexicon. Lancet Neurol 2010; 9: 1118-27.

5 Hardy JA, Higgins GA. Alzheimer's disease: the amyloid cascade hypothesis. Science 1992; 256: 184-5.

6 Sperling RA, Aisen PS, Beckett LA, et al. Toward defining the preclinical stages of Alzheimer's disease: recommendations from the National Institute on Aging-Alzheimer's Association workgroups on diagnostic guidelines for Alzheimer's disease. Alzheimers Dement 2011; 7: 280-92.

7 Dubois B, Hampel H, Feldman HH, et al. Preclinical Alzheimer's disease: Definition, natural history, and diagnostic criteria. Alzheimer's Dement 2016; 12: 292-323.

8 Jack CR, Bennett DA, Blennow K, et al. A/T/N: An unbiased descriptive classification scheme for Alzheimer disease biomarkers. Neurology. 2016; 87: 539-47.

9 Frisoni GB, Ritchie C, Carrera E, et al. Re-aligning scientific and lay narratives of Alzheimer's disease. Lancet Neurol 2019; 18: 918-9.

10 Rabinovici GD, Carrillo MC. Biomarker-Informed Treatment Decisions in Cognitively Impaired Patients Do Not Apply to Preclinical Alzheimer Disease. JAMA Intern Med 2019; 179: 1736-7.

11 Hyman BT, Phelps CH, Beach TG, et al. National Institute on Aging-Alzheimer's Association guidelines for the neuropathologic assessment of Alzheimer's disease. Alzheimers Dement 2012; 8: 1-13.

12 Robinson JL, Lee EB, Xie SX, et al. Neurodegenerative disease concomitant proteinopathies are prevalent, age-related and APOE4-associated. Brain 2018; 141: 218193.

13 Yokota O, Miki T, Ikeda C, et al. Neuropathological comorbidity associated with argyrophilic grain disease. Neuropathology 2018; 38: 82-97.

14 Ossenkoppele R, Lyoo CH, Jester-Broms J, et al. Assessment of Demographic, Genetic, and Imaging Variables Associated with Brain Resilience and Cognitive Resilience to Pathological Tau in Patients with Alzheimer Disease. JAMA Neurol 2020; 77: 632-42.

15 Karanth S, Karanth S, Nelson PT, et al. Prevalence and Clinical Phenotype of Quadruple Misfolded Proteins in Older Adults. JAMA Neurol 2020; 40536: 1-9.

16 Nelson PT, Dickson DW, Trojanowski JQ, et al. Limbic-predominant age-related TDP-43 encephalopathy (LATE): Consensus working group report. Brain 2019; 142: 1503-27.

17 Jessen F, Amariglio RE, Buckley RF, et al. The characterisation of subjective cognitive decline. Lancet Neurol 2020; 4422: 1-8.

18 Braak H, Thal DR, Ghebremedhin E, Del Tredici K. Stages of the pathologic process in Alzheimer disease: age categories from 1 to 100 years. J Neuropathol Exp Neurol 2011; 
70: $960-9$.

19 Whitehouse PJ, George D (Daniel R. The myth of Alzheimer's : what you aren't being told about today's most dreaded diagnosis. St. Martin's Press, 2008.

20 Saint Jean O, Favereau E. Alzheimer, le grand leurre. Paris: Michalon, 2018.

21 Small SA, Petsko GA. Endosomal recycling reconciles the Alzheimer's disease paradox. Sci Transl Med 2020; 12: eabb1717.

22 van der Kant R, Goldstein LSB, Ossenkoppele R. Amyloid- $\beta$-independent regulators of tau pathology in Alzheimer disease. Nat Rev Neurosci 2020; 21: 21-35.

23 Reitz C, Mayeux R. Alzheimer disease: Epidemiology, diagnostic criteria, risk factors and biomarkers. Biochem. Pharmacol. 2014; 88: 640-51.

24 Brookmeyer R, Abdalla N. Estimation of lifetime risks of Alzheimer's disease dementia using biomarkers for preclinical disease. Alzheimer's Dement 2018; 14: 981-8.

25 Arenaza-Urquijo EM, Vemuri P. Resistance vs resilience to Alzheimer disease. Neurology 2018; 90: 695-703.

26 Kunkle BW, Grenier-Boley B, Sims R, et al. Genetic meta-analysis of diagnosed Alzheimer's disease identifies new risk loci and implicates $\mathrm{A} \beta$, tau, immunity and lipid processing. Nat Genet 2019; 51: 414-30.

27 Jansen IE, Savage JE, Watanabe K, et al. Genome-wide meta-analysis identifies new loci and functional pathways influencing Alzheimer's disease risk. Nat Genet 2019; 51: 40413.

28 Hamelin L, Lagarde J, Dorothée G, et al. Distinct dynamic profiles of microglial activation are associated with progression of Alzheimer's disease. Brain 2018; 141: 1855-70.

29 Monsell SE, Mock C, Fardo DW, et al. Genetic Comparison of Symptomatic and Asymptomatic Persons With Alzheimer Disease Neuropathology. Alzheimer Dis Assoc Disord 2017; 31: 232-8.

30 Medina M, Khachaturian ZS, Rossor M, Avila J, Cedazo-Minguez A. Toward common mechanisms for risk factors in Alzheimer's syndrome. Alzheimer's Dement Transl Res Clin Interv 2017; 3: 571-8.

31 Swanson CJ, Zhang Y, Dhadda S, et al. DT-01-07: TREATMENT OF EARLY AD SUBJECTS WITH BAN2401, AN ANTI-A $\beta$ PROTOFIBRIL MONOCLONAL ANTIBODY, SIGNIFICANTLY CLEARS AMYLOID PLAQUE AND REDUCES CLINICAL DECLINE. Alzheimer's Dement 2018; 14: P1668.

32 Perk J, De Backer G, Gohlke H, et al. European Guidelines on cardiovascular disease prevention in clinical practice (version 2012). The Fifth Joint Task Force of the European Society of Cardiology and Other Societies on Cardiovascular Disease Prevention in Clinical Practice (constituted by re. Eur Heart J 2012; 33: 1635-701.

33 Desikan RS, Fan CC, Wang Y, et al. Genetic assessment of age-associated Alzheimer disease risk: Development and validation of a polygenic hazard score. PLOS Med 2017; 14: e1002258.

34 van Maurik IS, Slot RER, Verfaillie SCJ, et al. Personalized risk for clinical progression in cognitively normal subjects - The ABIDE project. Alzheimer's Res Ther 2019; 11: 1-9.

35 Villeneuve S, Rabinovici GD, Cohn-Sheehy BI, et al. Existing Pittsburgh Compound-B positron emission tomography thresholds are too high: Statistical and pathological evaluation. Brain 2015; 138: 2020-33.

36 Klunk WE, Koeppe RA, Price JC, et al. The Centiloid project: Standardizing quantitative amyloid plaque estimation by PET. Alzheimer's Dement 2015; 11: 1-15.e4.

37 Villain N, Chételat G, Grassiot B, et al. Regional dynamics of amyloid- $\beta$ deposition in 
healthy elderly, mild cognitive impairment and Alzheimer's disease: a voxelwise PiB-PET longitudinal study. Brain 2012; 135: 2126-39.

38 La Joie R, Ayakta N, Seeley WW, et al. Multisite study of the relationships between antemortem [ 11 C]PIB-PET Centiloid values and postmortem measures of Alzheimer's disease neuropathology. Alzheimer's Dement 2019; 15: 205-16.

39 Liebsch F, Kulic L, Teunissen C, et al. A 334 is a BACE1-derived degradation intermediate associated with amyloid clearance and Alzheimer's disease progression. Nat Commun 2019; 10. DOI:10.1038/s41467-019-10152-w.

40 Palmqvist S, Mattsson N, Hansson O. Cerebrospinal fluid analysis detects cerebral amyloid- $\beta$ accumulation earlier than positron emission tomography. Brain 2016; 139: 1226-36.

41 Duyckaerts C, Hauw JJ. Prevalence, incidence and duration of Braak's stages in the general population: Can we know? Neurobiol Aging 1997; 18: 362-9. Jack CR, Wiste HJ, Therneau TM, et al. Associations of Amyloid, Tau, and Neurodegeneration Biomarker Profiles with Rates of Memory Decline among Individuals Without Dementia. JAMA - J Am Med Assoc 2019; 55905: 2316-25.

43 Fleisher AS, Pontecorvo MJ, Devous MD, et al. Positron Emission Tomography Imaging with [18F]flortaucipir and Postmortem Assessment of Alzheimer Disease Neuropathologic Changes. JAMA Neurol 2020; : 1-11.

44 Mattsson-Carlgren N, Andersson E, Janelidze S, et al. A $\beta$ deposition is associated with increases in soluble and phosphorylated tau that precede a positive Tau PET in Alzheimer's disease. Sci Adv 2020; 6. DOI:10.1126/sciadv.aaz2387. Palmqvist S, Janelidze S, Quiroz YT, et al. Discriminative Accuracy of Plasma Phosphotau217 for Alzheimer Disease vs Other Neurodegenerative Disorders. JAMA - J Am Med Assoc 2020; 324: 772-81.

46 Chipi E, Salvadori N, Farotti L, Parnetti L. Biomarker-based signature of alzheimer's disease in pre-MCI individuals. Brain Sci 2019; 9: 1-22. Zhang S, Smailagic N, Hyde C, et al. 11C-PIB-PET for the early diagnosis of Alzheimer's disease dementia and other dementias in people with mild cognitive impairment (MCI). Cochrane Database Syst. Rev. 2014; 2014. DOI:10.1002/14651858.CD010386.pub2.

Ritchie C, Smailagic N, Noel-Storr AH, et al. Plasma and cerebrospinal fluid amyloid beta for the diagnosis of Alzheimer's disease dementia and other dementias in people with mild cognitive impairment (MCI). Cochrane Database Syst Rev 2014; 2014. DOI:10.1002/14651858.CD010386.pub2.

49 Martínez G, Vernooij RW, Fuentes Padilla P, Zamora J, Flicker L, Bonfill Cosp X. 18F PET with florbetaben for the early diagnosis of Alzheimer's disease dementia and other dementias in people with mild cognitive impairment (MCI). Cochrane Database Syst Rev 2017; 2017. DOI:10.1002/14651858.CD010386.

50 Martínez G, Vernooij RWM, Fuentes Padilla P, Zamora J, Flicker L, Bonfill Cosp X. 18F PET with flutemetamol for the early diagnosis of Alzheimer's disease dementia and other dementias in people with mild cognitive impairment (MCI). Cochrane Database Syst. Rev. 2017; 2017. DOI:10.1002/14651858.CD012884.

51 Martínez G, Vernooij RW, Fuentes Padilla P, Zamora J, Bonfill Cosp X, Flicker L. 18F PET with florbetapir for the early diagnosis of Alzheimer's disease dementia and other dementias in people with mild cognitive impairment (MCI). Cochrane Database Syst Rev database Syst Rev 2017; 11: CD012216.

52 Ritchie C, Smailagic N, Noel-Storr AH, Ukoumunne O, Ladds EC, Martin S. CSF tau and 
the CSF tau/ABeta ratio for the diagnosis of Alzheimer's disease dementia and other dementias in people with mild cognitive impairment (MCI). Cochrane Database Syst Rev 2017; 2017. DOI:10.1002/14651858.CD010386.

53 Jang H, Park J, Woo S, et al. Prediction of fast decline in amyloid positive mild cognitive impairment patients using multimodal biomarkers. NeuroImage Clin 2019; 24: 101941.

54 Insel PS, Weiner M, Scott MacKin R, et al. Determining clinically meaningful decline in preclinical Alzheimer disease. Neurology 2019; 93: E322-33.

55 Ebenau J, Timmers T, Wesselman LMP, et al. ATN-classification and clinical progression in subjective cognitive decline: the SCIENCe project. Neurology 2020.

Slot RER, Sikkes SAM, Berkhof J, et al. Subjective cognitive decline and rates of incident Alzheimer's disease and non-Alzheimer's disease dementia. Alzheimer's Dement 2019; 15: 465-76.

57 Balash Y, Mordechovich M, Shabtai H, Giladi N, Gurevich T, Korczyn AD. Subjective memory complaints in elders: depression, anxiety, or cognitive decline? Acta Neurol Scand 2013; 127: 344-50.

58 Jansen WJ, Ossenkoppele R, Knol DL, et al. Prevalence of cerebral amyloid pathology in persons without dementia: A meta-analysis. JAMA - J Am Med Assoc 2015; 313: 1924-38.

59 Verity R, Kirk A, O’Connell ME, Karunanayake C, Morgan DG. The Worried Well? Characteristics of Cognitively Normal Patients Presenting to a Rural and Remote Memory Clinic. Can J Neurol Sci 2018; 45: 158-67.

60 van der Flier WM, Pijnenburg YAL, Prins N, et al. Optimizing patient care and research: The Amsterdam dementia cohort. J Alzheimer's Dis 2014; 41: 313-27.

61 Hejl A, Høgh P, Waldemar G. Potentially reversible conditions in 1000 consecutive memory clinic patients. J Neurol Neurosurg Psychiatry 2002; 73: 390-4.

62 Mozersky J, Sankar P, Harkins K, Hachey S, Karlawish J. Comprehension of an elevated amyloid positron emission tomography biomarker result by cognitively normal older adults. JAMA Neurol 2018; 75: 44-50.

63 Epelbaum S, Paquet C, Hugon J, et al. How many patients are eligible for diseasemodifying treatment in Alzheimer's disease? A French national observational study over 5 years. BMJ Open 2019; 9. DOI:10.1136/bmjopen-2019-029663.

64 Schermer MHN, Richard E. On the reconceptualization of Alzheimer's disease. Bioethics 2019; 33: 138-45.

65 MetLife Foundation. What America Thinks MetLife Foundation Alzheimer's Survey. $2011 \mathrm{https} / /$ www.metlife.com/content/dam/metlifecom/us/homepage/corporateresponsibility/foundation-prior-projects/prior-commitments/alzheimers-2011.pdf.

66 Dubois B, Albert ML. Amnestic MCI or prodromal Alzheimer's disease? Lancet Neurol 2004; 3: 246-8.

67 Crutch SJ, Schott JM, Rabinovici GD, et al. Consensus classification of posterior cortical atrophy. Alzheimer's Dement 2017; 13: 870-84.

68 Gorno-Tempini ML, Hillis AE, Weintraub S, et al. Classification of primary progressive aphasia and its variants. Neurology 2011; 76: 1006-14.

69 Bergeron D, Gorno-Tempini ML, Rabinovici GD, et al. Prevalence of amyloid- $\beta$ pathology in distinct variants of primary progressive aphasia. Ann Neurol 2018; 84: 729 40 .

70 Ossenkoppele R, Pijnenburg YAL, Perry DC, et al. The behavioural/dysexecutive variant of Alzheimer's disease: clinical, neuroimaging and pathological features. Brain 2015; 138: 2732-49. 
71 Perry DC, Brown JA, Possin KL, et al. Clinicopathological correlations in behavioural variant frontotemporal dementia. Brain 2017; 140: 3329-45.

72 Armstrong MJ, Litvan I, Lang AE, et al. Criteria for the diagnosis of corticobasal degeneration. Neurology 2013; 80: 496-503.

73 Lee SE, Rabinovici GD, Mayo MC, et al. Clinicopathological correlations in corticobasal degeneration. Ann Neurol 2011; 70: 327-40.

74 Mesulam MM, Weintraub S, Rogalski EJ, Wieneke C, Geula C, Bigio EH. Asymmetry and heterogeneity of Alzheimer's and frontotemporal pathology in primary progressive aphasia. Brain 2014; 137: 1176-92.

75 Villain N, Dubois B. Alzheimer's Disease Including Focal Presentations. Semin Neurol 2019; 39: 213-26.

76 Jang KT, Choe GY, Suh YL, Chi JG. Cerebral Amyloid Angiopathy: A report of two cases. Korean J Pathol 1999; 33: 741-4.

77 Bell WR, An Y, Kageyama Y, et al. Neuropathologic, genetic, and longitudinal cognitive profiles in primary age-related tauopathy (PART) and Alzheimer's disease. Alzheimer's Dement 2019; 15: 8-16.

78 Toledo JB, Zetterberg H, Van Harten AC, et al. Alzheimer's disease cerebrospinal fluid biomarker in cognitively normal subjects. Brain 2015; 138: 2701-15.

79 Mattsson-Carlgren N, Leuzy A, Janelidze S, et al. The implications of different approaches to define AT(N) in Alzheimer disease. Neurology 2020; 0: 10.1212/WNL.0000000000009485.

80 Antonell A, Tort-Merino A, Ríos J, et al. Synaptic, axonal damage and inflammatory cerebrospinal fluid biomarkers in neurodegenerative dementias. Alzheimer's Dement 2019; $: 1-12$.

81 Nakamura A, Kaneko N, Villemagne VL, et al. High performance plasma amyloid- $\beta$ biomarkers for Alzheimer's disease. Nature 2018; 554: 249-54.

82 Dai MH, Zheng H, Zeng LD, Zhang Y. The genes associated with early-onset Alzheimer's disease. Oncotarget. 2018; 9: 15132-43.

83 Yu JT, Li JQ, Suckling J, et al. Frequency and longitudinal clinical outcomes of Alzheimer's AT(N) biomarker profiles: A longitudinal study. Alzheimer's Dement 2019; 15: $1208-17$.

84 Younes L, Albert M, Moghekar A, Soldan A, Pettigrew C, Miller MI. Identifying changepoints in biomarkers during the preclinical phase of Alzheimer's disease. Front Aging Neurosci 2019; 11: 1-11.

85 Jessen F, Kleineidam L, Wolfsgruber S, et al. Prediction of dementia of Alzheimer type by different types of subjective cognitive decline. Alzheimer's Dement 2020; 16: 1745-9.

86 Caselli RJ, Chen K, Locke DEC, et al. Subjective cognitive decline: Self and informant comparisons. Alzheimer's Dement 2014; 10: 93-8.

87 Niemantsverdriet E, Feyen BFE, Le Bastard N, et al. Added Diagnostic Value of Cerebrospinal Fluid Biomarkers for Differential Dementia Diagnosis in an AutopsyConfirmed Cohort. J Alzheimers Dis 2018; 63: 373-81.

88 Iacono D, Resnick SM, Brien RO, et al. Mild Cognitive Impairment and Asymptomatic Alzheimer Disease Subjects : Equivalent ABeta-Amyloid and Tau Loads With Divergent Cognitive Outcomes. J Neuropathol Exp Neurol 2014; 73: 295-304.

89 Perez-Nievas BG, Stein TD, Tai HC, et al. Dissecting phenotypic traits linked to human resilience to Alzheimer's pathology. Brain 2013; 136: 2510-26.

90 Knopman DS, Gottesman RF, Sharrett AR, et al. Mild cognitive impairment and dementia 
prevalence: The Atherosclerosis Risk in Communities Neurocognitive Study. Alzheimer's Dement Diagnosis, Assess Dis Monit 2016; 2: 1-11.

91 Timmers T, Ossenkoppele R, Wolters EE, et al. Associations between quantitative [18F]flortaucipir tau PET and atrophy across the Alzheimer's disease spectrum. Alzheimer's Res Ther 2019; 11: 1-12.

92 Maass A, Landau S, Horng A, et al. Comparison of multiple tau-PET measures as biomarkers in aging and Alzheimer's disease. Neuroimage 2017; 157: 448-63.

93 Lowe VJ, Bruinsma TJ, Min HK, et al. Elevated medial temporal lobe and pervasive brain tau-PET signal in normal participants. Alzheimer's Dement Diagnosis, Assess Dis Monit 2018; 10: 210-6.

94 Burnham SC, Bourgeat P, Doré V, et al. Clinical and cognitive trajectories in cognitively healthy elderly individuals with suspected non-Alzheimer's disease pathophysiology (SNAP) or Alzheimer's disease pathology: a longitudinal study. Lancet Neurol 2016; 15: 1044-53.

95 Albert M, Zhu Y, Moghekar A, et al. Predicting progression from normal cognition to mild cognitive impairment for individuals at 5 years. Brain 2018; 141: 877-87.

96 Dubois B, Epelbaum S, Nyasse F, et al. Cognitive and neuroimaging features and brain $\beta$ amyloidosis in individuals at risk of Alzheimer's disease (INSIGHT-preAD): a longitudinal observational study. Lancet Neurol 2018; 17: 335-46.

97 Sperling RA, Mormino EC, Schultz AP, et al. The impact of amyloid-beta and tau on prospective cognitive decline in older individuals. Ann Neurol 2019; 85: 181-93.

98 Parnetti L, Chipi E, Salvadori N, D’Andrea K, Eusebi P. Prevalence and risk of progression of preclinical Alzheimer's disease stages: A systematic review and metaanalysis. Alzheimer's Res Ther 2019; 11: 1-13.

99 Vogel JW, Doležalová MV, La Joie R, et al. Subjective cognitive decline and $\beta$-amyloid burden predict cognitive change in healthy elderly. Neurology 2017; 89: 2002-9.

100 Hanseeuw BJ, Betensky RA, Jacobs HIL, et al. Association of Amyloid and Tau with Cognition in Preclinical Alzheimer Disease: A Longitudinal Study. JAMA Neurol 2019; 76: $915-24$.

101 Jack CR, Wiste HJ, Schwarz CG, et al. Longitudinal tau PET in ageing and Alzheimer's disease. Brain 2018; 141: 1517-28.

102 Crary JF, Trojanowski JQ, Schneider JA, et al. Primary age-related tauopathy (PART): a common pathology associated with human aging. Acta Neuropathol 2014; 128: 755-66.

103 Raj A, LoCastro E, Kuceyeski A, Tosun D, Relkin N, Weiner M. Network Diffusion Model of Progression Predicts Longitudinal Patterns of Atrophy and Metabolism in Alzheimer's Disease. Cell Rep 2015; 10: 359-69.

104 Veitch DP, Weiner MW, Aisen PS, et al. Understanding disease progression and improving Alzheimer's disease clinical trials: Recent highlights from the Alzheimer's Disease Neuroimaging Initiative. Alzheimer's Dement 2019; 15: 106-52.

105 Saddiki H, Fayosse A, Cognat E, et al. Age and the association between apolipoprotein E genotype and Alzheimer disease: a cerebrospinal fluid biomarker-based case-control study. PLoS Med 2020; 17. DOI:10.1371/JOURNAL.PMED.1003289.

106 Albert MS, DeKosky ST, Dickson D, et al. The diagnosis of mild cognitive impairment due to Alzheimer's disease: recommendations from the National Institute on AgingAlzheimer's Association workgroups on diagnostic guidelines for Alzheimer's disease. Alzheimers Dement 2011; 7: 270-9.

107 McKhann GM, Knopman DS, Chertkow H, et al. The diagnosis of dementia due to 
Alzheimer's disease: recommendations from the National Institute on Aging-Alzheimer's Association workgroups on diagnostic guidelines for Alzheimer's disease. Alzheimers Dement 2011; 7: 263-9.

108 Dubois B, Feldman HH, Jacova C, et al. Advancing research diagnostic criteria for Alzheimer's disease: The IWG-2 criteria. Lancet Neurol 2014; 13: 614-29. 


\section{Author's contribution}

BD and NV equally contributed to the Manuscript.

$\mathrm{BD}$ and $\mathrm{NV}$ conceptualised, performed data curation, wrote the original draft, and performed revision and editing of the Manuscript.

HHF conceptualised, wrote the original draft, and performed revision and editing of the Manuscript.

GBF, GDR, MS, SC, AB, SB, SE, MT, MOH, AN, KB, DG, YS, CCR, SS, LSS, JLC conceptualised and performed revision and editing of the Manuscript.

Each of the authors has approved the final version. The corresponding author had final responsibility for the decision to submit for publication. 


\section{Panel 1 - Evidence limiting the predictive accuracy of amyloid and tau lesions for a further cognitive decline in cognitively unimpaired subjects}

\section{A - Cross-sectional data}

There is an overlap between AD pathological changes in cognitively normal subjects and in patients with AD dementia.

\section{Post-mortem}

$>$ Numerous cognitively normal and impaired individuals have comparable burden of AD brain lesions, confirmed with large post-mortem cohorts using quantification and digital neuropathological methods ${ }^{88,89}$

$>$ All stages AD brain lesions (including both amyloid and tau lesions) are found in $2 / 3$ of subjects aged of 70 years in systematic post-mortem examination regardless of clinical status $^{18}$, well beyond the expected prevalence of having cognitive impairment $(30 \%)^{90}$.

$>$ Neurofibrillary tangles in the medial temporal regions are found in almost all cognitively unimpaired individual over 70 years old ${ }^{18,41 *}$

\section{Molecular neuro-imaging cohorts}

$>$ Numerous cognitively normal and impaired individuals have comparable amyloid and tau PET burden ${ }^{91,92}$.

$>$ Both amyloid and diffuse tau (i.e. outside the medial temporal lobe) pathologies are found in $19 \%$ of 576 cognitively unimpaired elderly subjects (mean age 71 years) ${ }^{93} * *$.

\section{B - Longitudinal molecular neuro-imaging data}

They are insufficient to predict an invariable occurrence of symptoms:

$>$ Amyloid positivity is associated to an overall cognitive decline although a majority of $(\mathrm{A}+)$ subjects remain cognitively stable over time even after several years $\mathrm{s}^{42.55,8,3,44,94-99 * * *}$ :

- INSIGHT Study: 83\% (73/88) of A (+) subjects (77 years at entry) had no changes in any cognitive, behavioural and neuro-imaging parameters compared to baseline or to A (-) individuals after a 5-year follow-up ${ }^{96}$;

- AIBL Study: 81\% (111/137) of amyloid positive subjects (75 years old at entry) remains cognitively unimpaired after a 6 -year follow-up (Hazard Ratio $=2 \cdot 27)^{94}$ in the AIBL study;

- Lifetime risk of AD dementia for cognitively unimpaired A (+) individuals ranged between 5 and $42 \%$ according to age and sex, from pooled data of 13 cohorts in US and Europe ${ }^{24}$.

Both amyloid and tau pathologies in cognitively unimpaired $(\mathrm{A}+\mathrm{T}+)$ individuals increases the risk for middle-term progression to prodromal AD or AD dementia****

- $35 \%(6 / 17)$ of $\mathrm{A}(+)$ cognitive unimpaired elderly progressed to MCI or AD dementia after 7 years of follow-up of a longitudinal amyloid and tau PET study ${ }^{100 * * * * * ;}$

- $(\mathrm{A}+\mathrm{T}+)$ status significantly increases the 5-year risk of clinical progression to a prodromal stage $(44.4 \% \text { vs. } 10 \cdot 7 \% \text {; } \mathrm{HR}=2 \cdot 8)^{83,84}$, even more in case of $(\mathrm{SCD})^{55}$;

- Longitudinal tau PET studies showed no or only minimal acceleration of tau tracer uptake in the following 1 or 2 years in $\mathrm{A}(+)$ versus $\mathrm{A}(-)$ cognitive unimpaired elderly $101 * * * * *$.

\footnotetext{
* Primary Age Related Tauopathy (PART) has emerged in the lexicon as an age-related normal occurrence of tauopathy in the absence or with a low extent of amyloid pathology (Thal ABeta Phase $\leq 2{ }^{102}$ ). The cognitive decline of these patients (who could be considered ( $\mathrm{T}+\mathrm{A} \pm$ ) according to sensitive in vivo detection methods of biomarkers ${ }^{78}$ ) is significantly slower than that of patients with $\mathrm{AD}^{77}$, a noteworthy finding indicating that low $(\mathrm{A}+)$ (i.e. Thal ABeta Phase $\leq 2$ ) associated with $(\mathrm{T}+$ ) does not necessarily lead to an accelerated cognitive decline and dementia.

**Probable intermediate or high level of AD pathology according to neuropathological criteria ${ }^{11}$
} 
*** This finding at the group-level may result from the admixture of a proportion of progressors with the $(\mathrm{A}+)$ non-progressors.

**** A significant proportion remains cognitively stable for some years limiting any prediction of when or whether such progression will take place in a given individual.

***** In this study there was no significant difference at baseline in term of the degree of tau PET tracer retention between the amyloid positive converters and non-converters, indicating that baseline tau levels were not a strong predictor of clinical evolution.

***** In apparent contradiction of the widely accepted disease model where the accumulation of brain amyloid lesions triggers the fast spreading of tau lesions outside the medial temporal lobes ${ }^{103}$. 


\section{Panel 2: Toward a personalized risk profile in Asymptomatic at-risk}

\section{1- Factors that may increase the risk of progression to AD}

- Increased Age

- Frailty

- Female sex

- Low education level

- Heterozygous $A P O E \& 4$ status

- Polygenic risk factors beyond $A P O E$

- Familial history of AD

- Memory complaint/SCD

- Magnitude of brain lesions, inferred from pathophysiological biomarker results especially if searched with PET

- Presence of markers of neurodegeneration (isolated hippocampal atrophy on MRI, FDG-PET hypometabolism or elevated CSF NFL...)

- Co-pathology

\section{2- Factors that may decrease the risk}

- Protective genes, such as the presence of the $A P O E \varepsilon 2$ allele and homozygous, $A P O E$ \&3 Christchurch, A673T APP Icelandic mutation

- High cognitive reserve

\section{3- Factors that need to be further confirmed}

- Pattern of neuroinflammation

- Functional brain marker of Cognitive Reserve (e.g. using fMRI connectivity)

- Lifestyle factors: physical activity, sleep, social activities...

- Psychiatric diseases (depression...) 
Table 2 - AD diagnosis in clinical setting

\begin{tabular}{|c|c|c|c|}
\hline $\begin{array}{l}\text { CLINICAL } \\
\text { PHENOTYPE }\end{array}$ & BIOMARKER & $\begin{array}{l}\text { Likelihood } \\
\text { of AD as a } \\
\text { primary } \\
\text { diagnosis }\end{array}$ & Further investigations \\
\hline \multirow{9}{*}{$\begin{array}{r}\text { Common AD } \\
\text { phenotypes (amnestic } \\
\text { variant, lvPPA, and } \\
\text { PCA) }\end{array}$} & $\mathrm{A}(+) \mathrm{T}(+)$ & $\begin{array}{l}\text { Highly } \\
\text { probable - } \\
\text { Established }\end{array}$ & None required \\
\hline & $\mathrm{A}(+) \mathrm{T}($ unknown) & Probable & Consider tau measure (PET, CSF) \\
\hline & $\mathrm{A}(+) \mathrm{T}(-)$ & Probable & Consider additional tau measure (PET, CSF) \\
\hline & $\mathrm{T}(+) \mathrm{A}($ unknown) & Possible & Consider amyloid measure (PET, CSF) \\
\hline & $\mathrm{T}(+) \mathrm{A}(-)$ & Possible & Consider additional amyloid measure (PET, CSF) \\
\hline & $\mathrm{A}(-) \mathrm{T}($ unknown) & Unlikely & Full etiology work-up* and consider tau measure (PET, CSF) \\
\hline & A(unknown) $\mathrm{T}(-)$ & Unlikely & Full etiology work-up* and consider amyloid measure (PET, CSF) \\
\hline & $\mathrm{A}(-) \mathrm{T}(-)$ & $\begin{array}{l}\text { Highly } \\
\text { unlikely - } \\
\text { Excluded }\end{array}$ & Full etiology work-up*\# \\
\hline & $\begin{array}{l}\text { A(unknown) } \\
\text { T(unknown) }\end{array}$ & $\begin{array}{l}\text { Unassessab } \\
\text { le }\end{array}$ & Consider tau and amyloid measures (PET, CSF) \\
\hline \multirow{6}{*}{$\begin{array}{r}\text { Uncommon AD } \\
\text { phenotypes } \\
\text { (behavioural- } \\
\text { dysexecutive variant, } \\
\text { CBS, nfvPPA, and } \\
\text { svPPA) }\end{array}$} & $\mathrm{A}(+) \mathrm{T}(+)$ & Probable & $\begin{array}{l}\text { None required } \\
\text { Careful follow-up needed: an incongruent phenotype and neurodegeneration } \\
\text { pattern should trigger a new etiology work-up* }\end{array}$ \\
\hline & $\mathrm{A}(+) \mathrm{T}($ unknown) & Possible & Consider tau measure (PET, CSF) \\
\hline & $\mathrm{A}(+) \mathrm{T}(-)$ & Possible & Consider additional tau measure (PET, CSF) \\
\hline & $\mathrm{T}(+) \mathrm{A}($ unknown) & Unlikely & Full etiology work-up* and consider amyloid measure (PET, CSF) \\
\hline & $\mathrm{T}(+) \mathrm{A}(-)$ & Unlikely & Full etiology work-up* \\
\hline & $\mathrm{A}(-) \mathrm{T}($ unknown) & $\begin{array}{l}\text { Highly } \\
\text { unlikely - }\end{array}$ & Full etiology work-up*\# \\
\hline
\end{tabular}




\begin{tabular}{|r|l|l|l|}
\hline \multirow{2}{*}{} & & Excluded & \\
\cline { 2 - 4 } & A(unknown) T(-) & $\begin{array}{l}\text { Highly } \\
\text { unlikely - } \\
\text { Excluded }\end{array}$ & Full etiology work-up*\# \\
\cline { 2 - 4 } & A(-) T(-) & $\begin{array}{l}\text { Highly } \\
\text { unlikely - } \\
\text { Excluded }\end{array}$ & Full etiology work-up*\# \\
\cline { 2 - 4 } & $\begin{array}{l}\text { A(unknown) } \\
\text { T(unknown) }\end{array}$ & $\begin{array}{l}\text { Unassessab } \\
\text { le }\end{array}$ & Consider tau and amyloid measures (PET, CSF) \\
\hline $\begin{array}{r}\text { Other phenotypes (eg } \\
\text { syndrome, Runtingardson }\end{array}$ & $\mathrm{A}(+)$ or/and T(+) & Unlikely & Full etiology work-up* \\
\cline { 2 - 4 } disease, ALS, etc) & $\begin{array}{l}\text { A(-) T(unknown) or } \\
\text { A(unknown) T(-) or } \\
\text { A(-) T(-) }\end{array}$ & $\begin{array}{l}\text { Highly } \\
\text { unlikely - } \\
\text { Excluded }\end{array}$ & Full etiology work-up* \\
\hline
\end{tabular}

Note that positivity status must rely on local laboratory standards (see text for details).

$\mathrm{A}=$ amyloid $; \mathrm{T}=$ tau $\mathrm{AD}=$ Alzheimer's disease $\operatorname{lvPPA}=$ logopenic variant of primary progressive aphasia; $\mathrm{PCA}=$ posterior cortical atrophy; bvFTD $=$ behavioural variant of fronto-temporal dementia; CBS = cortico-basal syndrome; nfvPPA = non-fluent variant of primary progressive aphasia; svPPA = semantic variant of primary progressive aphasia; DLB = dementia with Lewy body; ALS = amyotrophic lateral sclerosis; PET = positron emission tomography; CSF = cerebrospinal fluid.

* Full etiology work-up depends on the specific phenotype and can imply for example FDG-PET, dopamine imaging, progranulin serum dosage, genetic analysis, oculomotor recordings, electromyoneurography, etc

\# Consider a new AD biomarker investigation only in cases where you have a reasonable doubt regarding the validity of biomarkers' results 
Table 1: AD diagnosis according to the successive criteria proposals

\begin{tabular}{|c|c|c|c|c|c|c|c|}
\hline & $\begin{array}{c}\text { NINCDS } \\
1984^{2}\end{array}$ & $\begin{array}{l}\text { IWG } \\
2007^{3}\end{array}$ & $\begin{array}{l}\text { IWG } \\
2010^{4}\end{array}$ & $\begin{array}{c}\text { NIA-AA } \\
2011^{105,106}\end{array}$ & $\begin{array}{c}\text { IWG } \\
2014^{107}\end{array}$ & $\begin{array}{c}\text { IWG/AA } \\
2016^{7}\end{array}$ & $\begin{array}{c}\text { NIA-AA } \\
2018^{1}\end{array}$ \\
\hline $\begin{array}{l}\text { Criteria } \\
\text { mainly for }\end{array}$ & $\begin{array}{l}\text { Clinical } \\
\text { setting }\end{array}$ & Research & & $\begin{array}{c}\text { Research and } \\
\text { clinical } \\
\text { setting } \\
\end{array}$ & Research & Research & Research \\
\hline $\begin{array}{l}\text { Clinical } \\
\text { requirements }\end{array}$ & $\begin{array}{l}\text { Dementia, } \\
\text { (memory } \\
\text { changes, } \\
\text { another } \\
\text { cognitive } \\
\text { impairment) }\end{array}$ & $\begin{array}{l}\text { Amnestic Syndr. of } \\
\text { hippocampal type }\end{array}$ & $\begin{array}{l}\text { - Amnestic Syndr. of } \\
\text { hippocampal type } \\
\text { - Posterior cortical V } \\
\text { - Logopenic V } \\
\text { - Behav.-frontal V }\end{array}$ & $\begin{array}{l}\text { - MCI } \\
\text { (amnestic; } \\
\text { non amnestic) } \\
\text { - Dementia }\end{array}$ & $\begin{array}{l}\text { - Amnestic Syndr. of } \\
\text { hippocampal type } \\
\text { - Posterior corticalV } \\
\text { - Logopenic V } \\
\text { - Behav.-frontal V }\end{array}$ & NONE & NONE \\
\hline $\begin{array}{l}\text { Biological } \\
\text { requirements }\end{array}$ & NONE & $\begin{array}{l}\text { - CSF biomarkers } \\
\text { - MRI atrophy } \\
\text { - hypometabolism } \\
\text { FDG } \\
\text {-amyloid PET + }\end{array}$ & $\begin{array}{l}\text { - pathophysiological } \\
\text { markers: } \\
\text { CSF changes } \\
\text {. Amyloid PET + }\end{array}$ & $\begin{array}{l}\text { - amyloid } \\
\text { markers: } \\
\text { CSF, PET } \\
\text { - marker of } \\
\text { degeneration: } \\
\text { CSF tau/p-tau } \\
\text { FDG-PET, } \\
\text { MRI }\end{array}$ & $\begin{array}{l}\text { - CSF A } \beta \text { and tau } \\
\text { OR } \\
\text { - amyloid PET + }\end{array}$ & $\begin{array}{l}\text { - amyloid } \\
\text { marker (CSF, } \\
\text { PET) } \\
\text { AND } \\
\text {-tau markers } \\
\text { (CSF, PET) }\end{array}$ & $\begin{array}{l}\text { - amyloid } \\
\text { marker (CSF, } \\
\text { PET) } \\
\text { AND } \\
\text {-tau markers } \\
\text { (CSF, PET) }\end{array}$ \\
\hline
\end{tabular}


Supplementary Material 

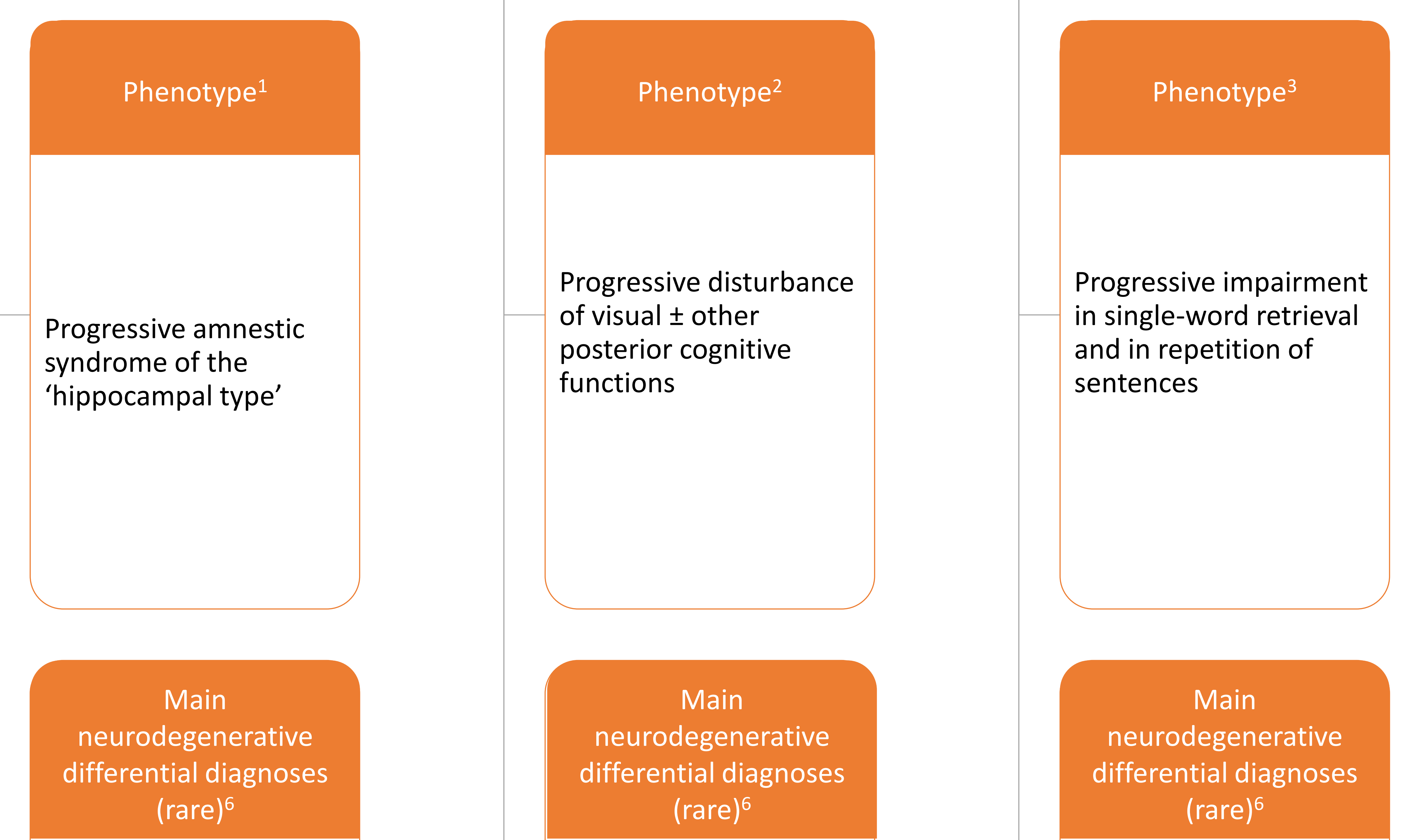

\section{- LBD}

- FTLD-Tau (CBD)

- Prion-associated diseases

- Atypical fTID-Tau or

TDP (17q21.31, MAPT,

GRN, C9ORF72

mutations or GGT)

- Atypical LBD

- Atypical CTE

- Prion-associated

diseases dysfunction

Main

neurodegenerative differential diagnoses $(\text { rare })^{6}$

FTLD-Tau (CBD) or$$
\text { TDP }
$$

- Atypical LBD

- Prion-associated diseases

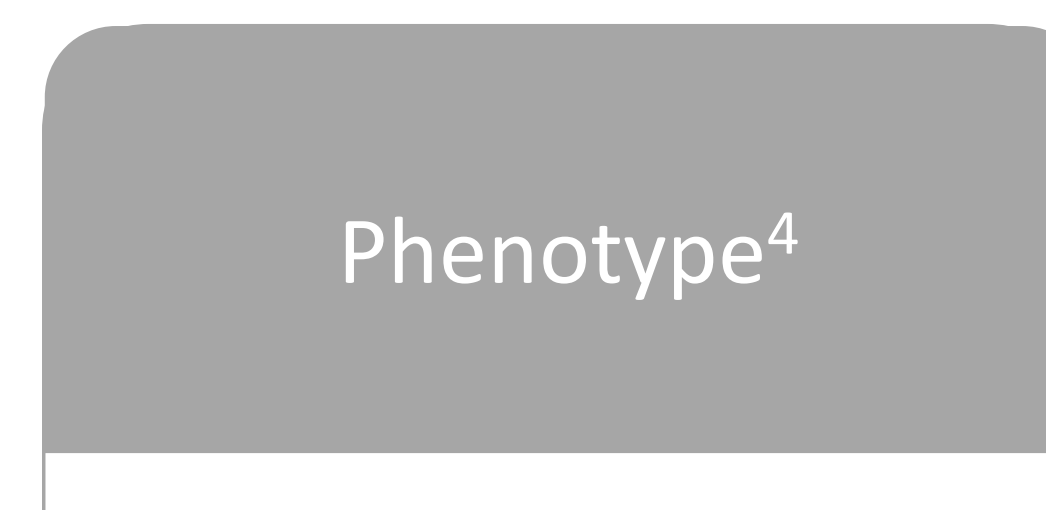

- Progressive apathy or behavioural

disinhibition and

stereotyped behaviours

- or progressive

predominant executive

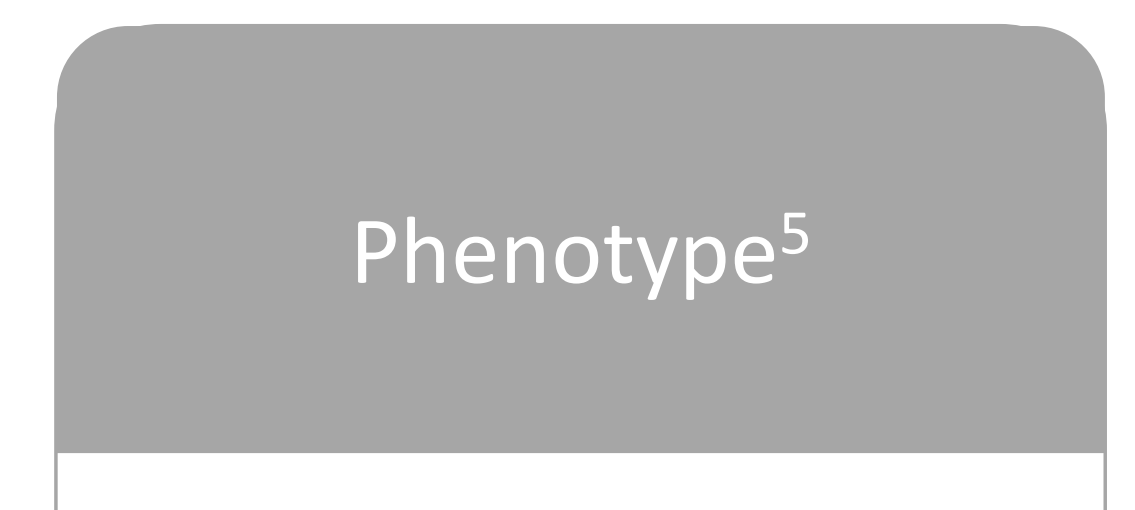

Progressive asymmetric clinical presentation

including limb rigidity or

akinesia, limb dystonia,

$\operatorname{limb}$ myoclonus,
orobuccal or limb

apraxia, cortical sensory

deficit, alien limb

phenomena
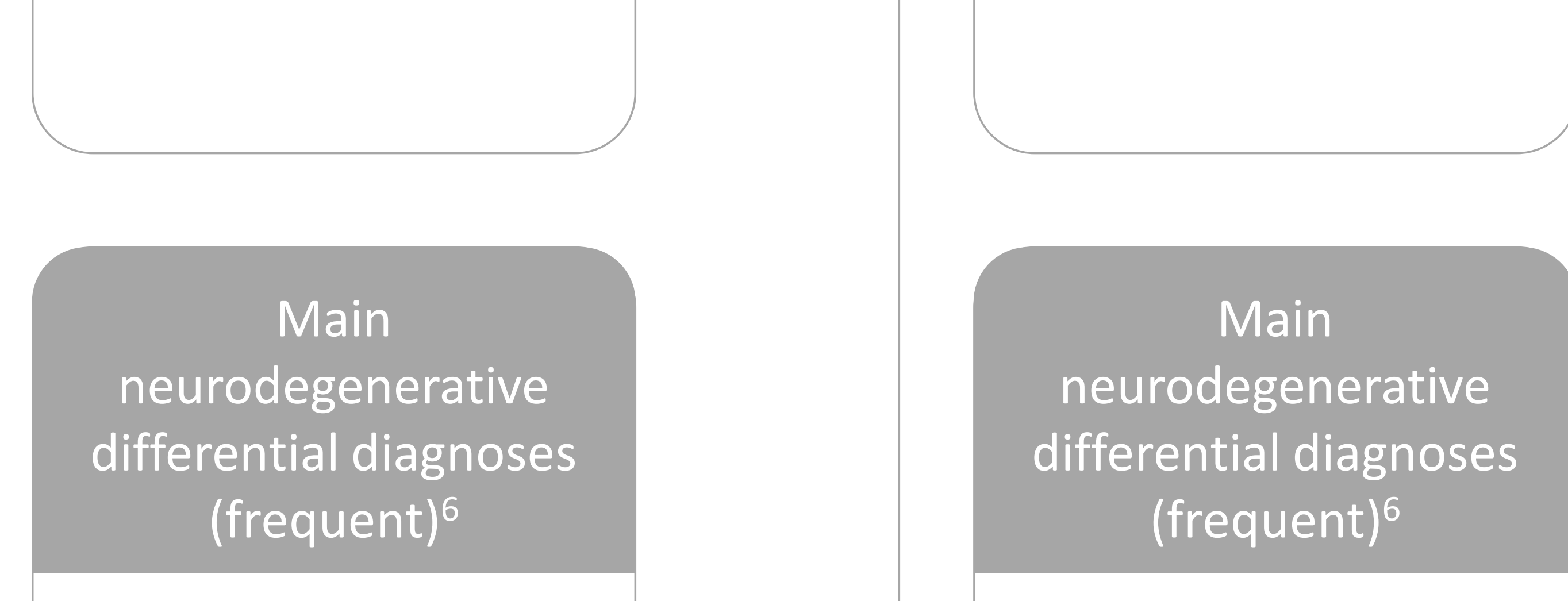

- Behavioural AD: FTLD-

Tau, TDP or FUS

- Dysexecutive AD:

FTLD, LBD, Parkinson's

disease, PSP, CBD,

Huntington's

disease...

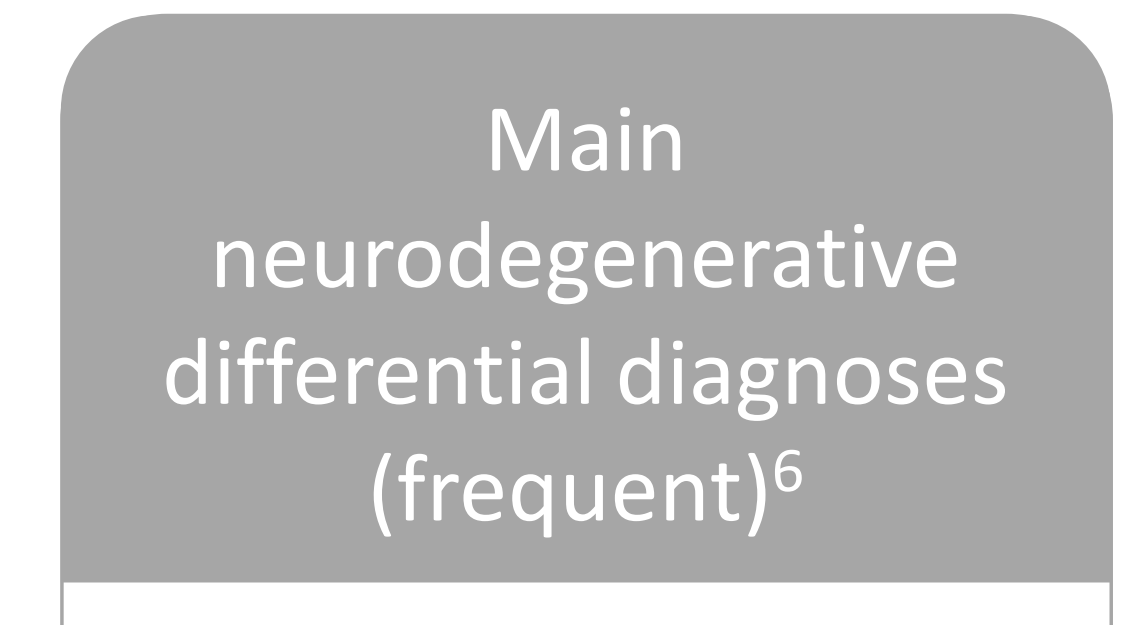

- FTLD-Tau (CBD, PSP)

- FTLD-TDP

- Atypical LBD
Phenotype $^{3}$

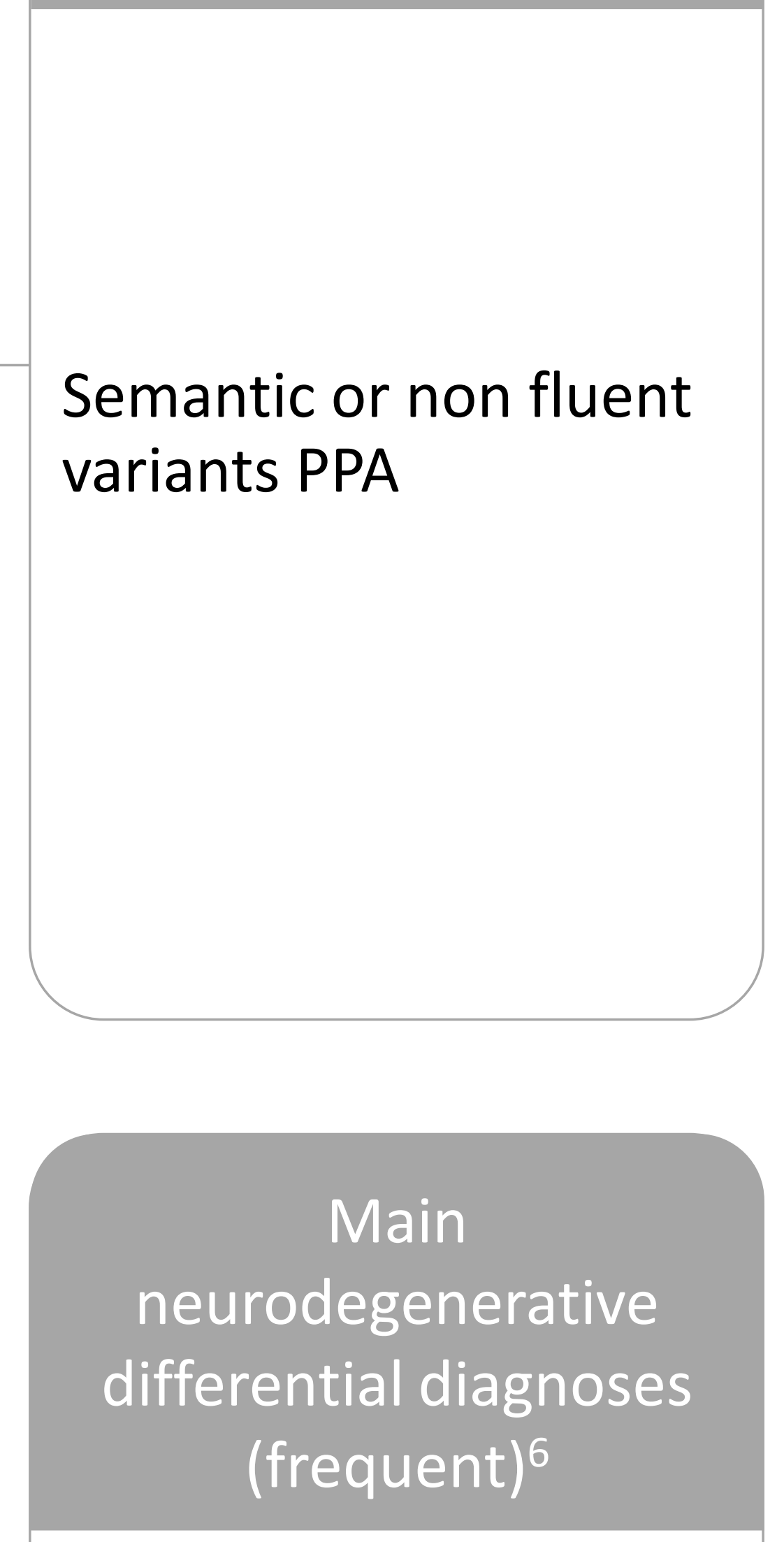

FTLD-Tau or TDP or

FUS

- Atypical LBD

- Prion-associated diseases 
Figure caption

Supplementary Figure. Common and uncommon clinical phenotypes of Alzheimer's disease $(A D)$ and the relative frequency of differential diagnoses for each phenotype (including only neurodegenerative diseases). Common phenotypes are phenotypes where $A D$ is a common underlying pathology, while uncommon phenotypes are phenotypes where $A D$ is not the most frequent underlying pathology. LATE = limbic-predominant age-related TDP-43 encephalopathy; PART = primary age-related tauopathy; $A G D=$ argyrophilic grain disease; FTLD = frontotemporal lobar degeneration; $L B D=$ Lewy body disease $; C T E=$ chronic traumatic encephalopathy; $\mathrm{PRNP}=\mathrm{PRioN}$ protein; $\mathrm{CBD}=$ cortico-basal degeneration; $\mathrm{TDP}=$ TAR DNA-binding protein; FUS = fused in sarcoma; PSP = progressive supranuclear palsy; PPA = primary progressive aphasia' 
1 Dubois B, Feldman $\mathrm{HH}$, Jacova $\mathrm{C}$, et al. Advancing research diagnostic criteria for Alzheimer's disease: The IWG-2 criteria. Lancet Neurol 2014; 13: 614-29.

2 Crutch SJ, Schott JM, Rabinovici GD, et al. Consensus classification of posterior cortical atrophy. Alzheimer's Dement 2017; 13: 870-84.

3 Gorno-Tempini ML, Hillis AE, Weintraub S, et al. Classification of primary progressive aphasia and its variants. Neurology 2011; 76: 1006-14.

4 Ossenkoppele R, Pijnenburg YAL, Perry DC, et al. The behavioural/dysexecutive variant of Alzheimer's disease: clinical, neuroimaging and pathological features. Brain 2015; 138: 2732-49.

5 Armstrong MJ, Litvan I, Lang AE, et al. Criteria for the diagnosis of corticobasal degeneration. Neurology 2013; 80: 496-503.

6 Villain N, Dubois B. Alzheimer's Disease Including Focal Presentations. Semin Neurol 2019; 39: 213-26. 
Supplementary references - Panel 3

1 Leonenko G, Shoai M, Bellou E, et al. Genetic risk for alzheimer disease is distinct from genetic risk for amyloid deposition. Ann Neurol 2019; 86: 427-35.

2 Porter T, Burnham SC, Milicic L, et al. Utility of an Alzheimer's Disease Risk-Weighted Polygenic Risk Score for Predicting Rates of Cognitive Decline in Preclinical Alzheimer's Disease: A Prospective Longitudinal Study. J Alzheimer's Dis 2018; 66: 1193-211.

3 Carvalho DZ, St Louis EK, Knopman DS, et al. Association of excessive daytime sleepiness with longitudinal $\beta$-Amyloid accumulation in elderly persons without dementia. JAMA Neurol 2018; 75: 672-80.

4 Gatchel JR, Rabin JS, Buckley RF, et al. Longitudinal Association of Depression Symptoms with Cognition and Cortical Amyloid among Community-Dwelling Older Adults. JAMA Netw Open 2019; 2: 1-13.

5 Biddle KD, d'Oleire Uquillas F, Jacobs HIL, et al. Social Engagement and Amyloid- $\beta$ Related Cognitive Decline in Cognitively Normal Older Adults. Am J Geriatr Psychiatry 2019; 27: 1247-56.

6 Rabin JS, Klein H, Kirn DR, et al. Associations of Physical Activity and $\beta$-Amyloid with Longitudinal Cognition and Neurodegeneration in Clinically Normal Older Adults. JAMA Neurol 2019; 76: 1203-10.

7 Burnham SC, Bourgeat $P$, Doré $V$, et al. Clinical and cognitive trajectories in cognitively healthy elderly individuals with suspected non-Alzheimer's disease pathophysiology (SNAP) or Alzheimer's disease pathology: a longitudinal study. Lancet Neurol 2016; 15: 1044-53.

8 Lim YY, Kalinowski P, Pietrzak RH, et al. Association of ß-Amyloid and apolipoprotein e e4 with memory decline in preclinical Alzheimer disease. JAMA Neurol 2018; 75: 48894.

9 Dubois B, Epelbaum S, Nyasse F, et al. Cognitive and neuroimaging features and brain $\beta$-amyloidosis in individuals at risk of Alzheimer's disease (INSIGHT-preAD): a longitudinal observational study. Lancet Neurol 2018; 17: 335-46.

10 Albert $M$, Zhu Y, Moghekar A, et al. Predicting progression from normal cognition to mild cognitive impairment for individuals at 5 years. Brain 2018; 141: 877-87.

11 Jack CR, Wiste HJ, Therneau TM, et al. Associations of Amyloid, Tau, and Neurodegeneration Biomarker Profiles with Rates of Memory Decline among Individuals Without Dementia. JAMA - J Am Med Assoc 2019; 55905: 2316-25.

12 Monsell SE, Mock C, Roe CM, et al. Comparison of symptomatic and asymptomatic persons with Alzheimer disease neuropathology. Neurology 2013; 80: 2121-9.

13 Nelson PT, Dickson DW, Trojanowski JQ, et al. Limbic-predominant age-related TDP-43 encephalopathy (LATE): Consensus working group report. Brain 2019; 142: 1503-27. 
14 Ebenau J, Timmers T, Wesselman LMP, et al. ATN-classification and clinical progression in subjective cognitive decline: the SCIENCe project. Neurology 2020.

15 Vogel JW, Doležalová MV, La Joie R, et al. Subjective cognitive decline and $\beta$-amyloid burden predict cognitive change in healthy elderly. Neurology 2017; 89: 2002-9.

16 Buckley RF, Mormino EC, Amariglio RE, et al. Sex, amyloid, and APOE $\varepsilon 4$ and risk of cognitive decline in preclinical Alzheimer's disease: Findings from three wellcharacterized cohorts. Alzheimer's Dement 2018; 14: 1193-203.

17 Amariglio RE, Buckley RF, Mormino EC, et al. Amyloid-associated increases in longitudinal report of subjective cognitive complaints. Alzheimer's Dement Transl Res Clin Interv 2018; 4: 444-9.

18 Wallace LMK, Theou O, Godin J, Andrew MK, Bennett DA, Rockwood K. Investigation of frailty as a moderator of the relationship between neuropathology and dementia in Alzheimer's disease: a cross-sectional analysis of data from the Rush Memory and Aging Project. Lancet Neurol 2019; 18: 177-84. 